\title{
Potorostrongylus woyliei n. sp. (Nematoda: Cloacinidae) from the Brush-tailed Bettong Bettongia penicillata (Marsupialia) from Western Australia, Australia, with Comments on Potoroid-Potorostrongylid Associations and a Key to the Species of Potorostrongylus
}

\author{
LESLEY R. SMALES \\ School of Biological and Environmental Sciences, Central Queensland University, Rockhampton, \\ QLD 4702, Australia (e-mail: l.warner@cqu.edi.au)
}

ABSTRACT: Poturostrongy/is woyliei sp. n. (Nematoda: Cloacinidae), a new nematode from the stomach of the brush-tailed bettong Bettongia penitillara is described and a revised key to the genus provided. The new species most closely resembles Potorostrongylus finiaysoni Johnston and Mawson, 1939 and Potorostrongyilus temperatus Smales, 1997 but differs from both in the shape of the submedian lips, the length of the spicules, and the proportions of the elements of the ovejector. Each potoroid host species is associaled with a particular species of Potorostrungy/ns, suggesting coevolution of host and haiminth. Additional potoroid-potorostronglyid associations appear to be incidental infections resulting from sympatric host distribution.

KEY wORDS: Nematoda, Cloacinidae, Labiostrongylinea, Pororostrongylus, marsupial, brush-tailed bettong, Beffongio penicillata, Westem Australia, Australia.

The genus Potorostrongylus Johnston and Mawson, 1939 comprises species of the tribe Labiostrongylinea that parasitize potoroos and bettongs (Macropodidae: Potoroinae). The genus was revised by Smales (1997), who recognized 4 species: the type species, Potorostrongyltas finlaysoni Johnston and Mawson, 1939; Potorostrongylus aepyprymmus Mawson, 1974; Potorostrongylis temperatts Smales, 1997; and, Potorostrongylus tropicus Smales, 1997. All species of Potorostrongylis are known from hosts in eastem Australia.

The brush-tailed bettong, Betrongia penicillata Gray, 1837 is reduced to remnant populations in southwestern Australia (Christensen, 1995). Recent collections of helminths from $B$. penicillata include a fifth species of Potorostrongylis. This new species is described in this study and a rovised key to the genus provided. Additional nematode material from potoroos and bettongs held in the Commonwealth Scientific and Industrial Research Organization Wildlife Collection, Canberra, Australia (CSIRO), and the South Australian Museum, Adelaide, Australia (SAM), was also examined and the resulting host associations reported in this study.

\section{MATERIALS AND METHODS}

Specimens dissected from the stomachs of 2 brush-tailed bettongs were fixed in 10\% formalin and stored in $70 \%$ ethanol. Worms were examined after clearing in lactophenol. Figures were prepared with the aid of a drawing tabe and all mensurements made with the aid of an ocular micrometer. Unless otherwise indicated, measurements are presented its range values presented in micrometers followed parenthetically by the mean. Additional specimens held by CSIRO and SAM were examined and identified, providing previously unreported geographic range and host association data for Potorostrongylus. New and existing specimen material is deposited with CSIRO or SAM and is noted below. Host nomenclature follows Strahan (1995). Parasite nomenclature and terminology follows Chilton et al. (1997) and Beveridge $(1983,1987)$.

\section{RESULTS \\ New determinations of existing CSIRO and SAM specimens}

Specimens comprising lots CSIRO N986, N1235, $\mathrm{N} 1332$, and $\mathrm{N} 1362$ collected from the Tasmanian bettong, Bettongia grimarti (Desmarest, 1822), in Blessington, Tasmania, Australia $\left(41^{\circ} 31^{\prime} \mathrm{S} ; 147^{\circ} 24^{\prime} \mathrm{E}\right)$, Epping Forest, Tasmania, Australia $\left(41^{\circ} 45^{\prime} \mathrm{S}\right.$; $\left.147^{\circ} 21^{\prime} \mathrm{E}\right)$, and Kempton, Tasmania, Australia $\left(41^{\circ} 3 I^{\prime} S ; 147^{\circ} 12^{\prime}\right.$ E) were identified as $P$. semperatus. Specimens comprising CSIRO N3386 collected from the rufous bettong, Aepyprymnus rufeseens (Gray. 1837), in Grafton, New South Wales, Australia $\left(30^{\circ} 14^{\prime} \mathrm{S} ; \quad 150^{\circ} 147^{\prime} \mathrm{E}\right)$ were also identified as $P$. temperatus. This is the first record of $P$. temperatus infecting $A$. riffescens. In contrast, specimens comprising SAM AHC 32874 collected from a single specimen of $A$, rufescens in Mt. Fox, Queensland, Australia $\left(18^{\circ} 49^{\prime} \mathrm{S} ; 145^{\circ} 48^{\prime} \mathrm{E}\right)$ were identified as $P$. tropicus. Similarly, specimens comprising SAM AHC 11102, AHC 32873 collected from the northem bettong, Bettongia tropicu (Wakefield, 1967), in Cairns, Queensland, Australia (16 $55^{\prime} \mathrm{S} ; 145^{\circ} 46^{\prime} \mathrm{E}$ ) 
were identified as $P$. tropicus. Specimens comprising CSIRO N997, N1001, and N5075 collected from the long-nosed potoroo, Potorous tridactylus (Kerr, 1792), in Hobart, Tasmania, Australia $\left(41^{\circ} 29^{\prime} \mathrm{S} ; 147^{\circ} 52^{\prime} \mathrm{E}\right)$ and Chudleigh, Tasmania, Australia $\left(41^{\circ} 33^{\prime} \mathrm{S}\right.$; $146^{2} 28^{\prime} \mathrm{E}$ ) were identified as $P$. finlaysoni.

\section{Potorostrongylus woyliei sp. $\mathbf{n}$.} (Figs. 1-17)

\section{Descriptlon}

Cloacinidae Stossich, 1899; Cloacininae Stossich, 1899; Labiostrongylinea Beveridge, 1983. Relatively small worms, body with fine transverse cuticular striations. Cephalic extremity with 6 fleshy, welldeveloped lips with pulp cavities, bearing $V$-shaped cuticular ridges on outer surfaces; 4 submedian lips, tips wedge shaped each with single notch, bearing cephalic papilla on base (Figs. 4, 17); 2 lateral lips simple, bearing amphids; 2 interlabia, 1 dorsal, 1 ventral with $V$-shaped ridge but without pulp. Cervical cuticle inflated from base of lips to just anterior to nerve ring. Buccal capsule small, oval, wider than deep, does not extend beyond posterior level of lips. Esophagus long, one-ninth body length, nurrow, with ovoid terminal bulb; lining of esophagus strongly cuticularized at angles of triradiate lunen, forming 3 pairs of sclerotized plates in terminal bulb. Deirids short, setiform, 20 long, posterior to excretory pore, both postetior to nerve ring which encircles esaphagus at two-fifths its length.

Male (holotype and 3 paratypes): Length 8.6-10 (9.6) $\mathrm{mm}$; width 340-430 (380). Buccal capsule 17 deep, 12 wide. Esophagus 1,105-1,140 (1,090) long: terminal bulb 268 long, 175-200 (185) wide. Nerve ring $395-470(430)$, deirid 630,655 , excretory pore 610 from anterior end. Bursa prominent, lobes not separate, dorsal lobe longest, ventral lobes shortest. Ventroventral and ventrolateral rays fused for most of length, reaching margin of bursa; externolateral ray divergent from lateral trunk, aimost reaching margin of bursa; mediolateral and posterolateral rays fused, reaching margin of bursa; extemodorsal ray arising close to lateral trunk, not reaching margin of bursa; dorsal trunk stout, bifurcating at about one-third its length; lateral branches given off close to bifurcation, not reaching margin of bursa, terminal branches extending into lappets of the dorsal lobe; lateral branch of dorsal ray may have brancllet (Fig. 16). Spicules 680-985 (895) long, about one-eleventh body length, anterior extremities irregularly knobbed; dorsal tips slightly curved, blunt, striated alae extend- ing almost to tips. Genital cone small; anterior lip larger conical, bearing pair of lateral alae, posterior lip smaller, with fringe of 6 bifid projections. Gubernaculum not present; spicule sheath with paired lateral elongate and central cordate thickenings.

Female (allotype and 2 paratypes): Length 11-12 $\mathrm{mm}$; width 450-510. Buccal capsule, 12-15 deep, 17-20.5 wide. Esophagus 1,140-1,275 long; terminal bulb 290-305 long, 205-220 wide. Nerve ring 375485 , excretory pore $505-630$, deirids $630-670$ from anterior end. Body narrows at level of yulva, 9751,285 from tail tip; tail 605-750 long, ending in conical tip. Vulva close to anus, leading into broad short vagina $170-200$ long; ovejector with vestibule shorter than sphincter, infundibulum shorter than vestibule. Eggs thin shelled, ellipsoidal 76-83 long, 53-56 wide.

Fourth-stage larva, female (1 specimen): Length 4.3 $\mathrm{mm}$; width 165. Esophagus 830 long; terminal bulb 134 long, 37 wide, esophago-intestinal diverticula present. Nerve ring 380, excretory pore 445 from anterior end. Deirids not seen. Tail 375 long.

\section{Taxonomic summary}

Type host: Brush-tailed bettong, B. penicillata Gray, 1937.

Type locality: Batalling, Western Australia, Australia $\left(33^{\circ} 20^{\prime} \mathrm{S} ; 116^{\circ} 34^{\prime} \mathrm{E}\right)$.

Infection site: Stomach.

Collection date: 11 December 2001.

Specimens deposited: Holotype male (SAM AHC 32862), allotype fernale (SAM AHC 32863), paratypes (SAM AHC 32864).

Specimens examined: (CSIRO N3203) 2 males, 10 females from B. penicillata, from Perup, Western Australin, Australia, $\left(34^{\circ} 19^{\prime} \mathrm{S}, 116^{\circ} 27^{\prime} \mathrm{E}\right)$ collected 12 December 1990.

Etynology: The species is named from the indigenous nume for the host, the woylie.

\section{Key to the species of Potorostrongylus}

1a. Buccal capsule within lip region ................. 2

1b. Buccal capsule extends posterior to region of lips 


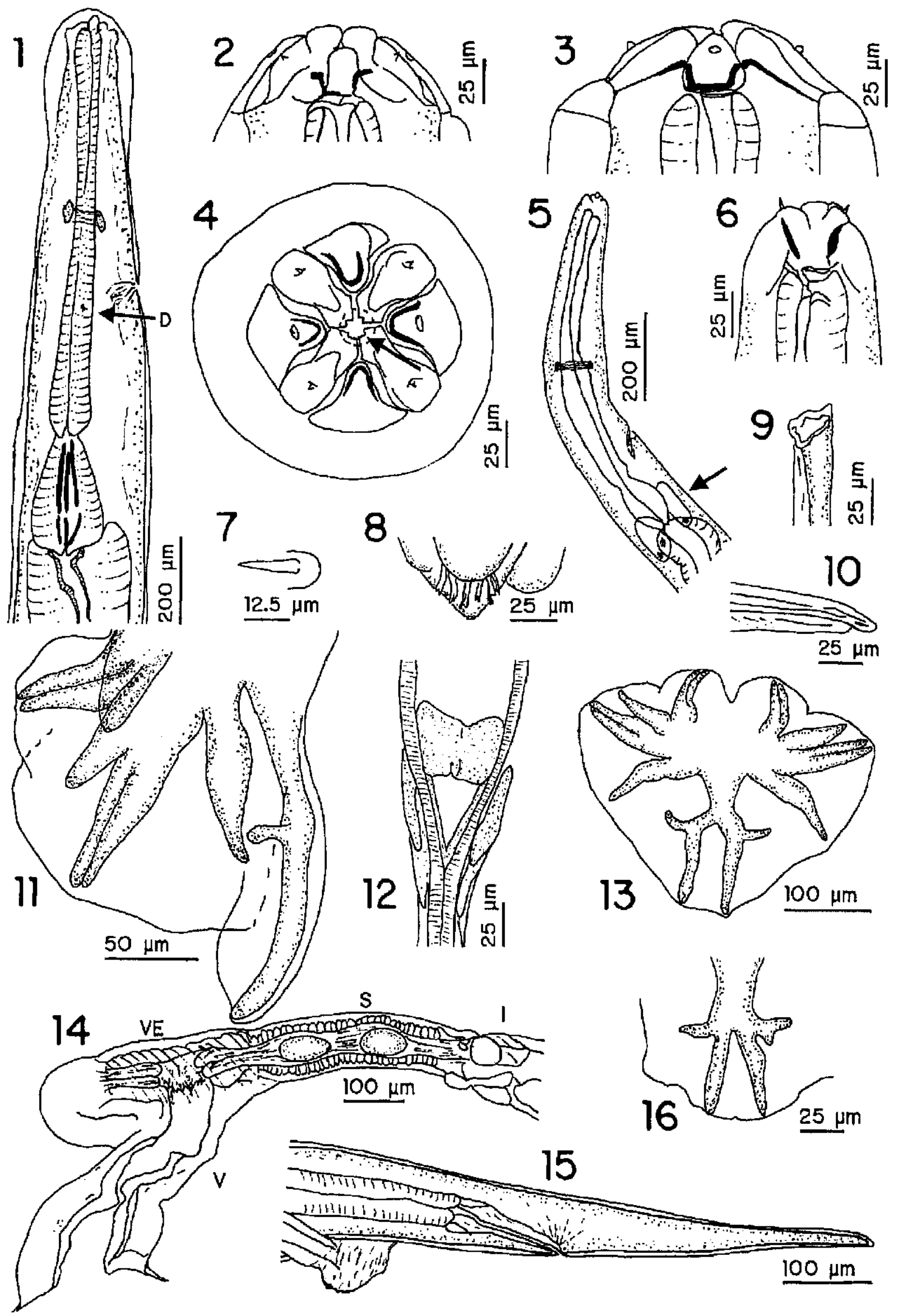




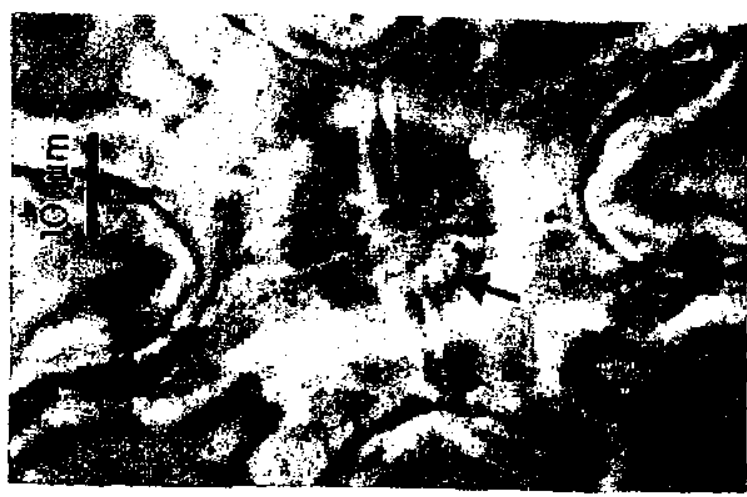

Figure 17. Potorostrongylus woyliei n. sp. from Bestongia penicillato in Western Australia. Cephalic end, en face view showing notched tips of submedian lips (alrow).

2a. Submedian lips with notched tips; spicules $<1,000$, one-eleventh body length, vagina $<230 \mu \mathrm{m}$......................... P. woyliei n. sp.

2b. Submedian lips with wedge-shaped tips, spicules $>1,000$, one-fifth to one-eightl body length, vagina $>230 \mu \mathrm{m}$ long

3a. Dorsal lobe of bursa longer than laterals; spicule tips straight; 3 pairs of bifid projections on posterior lip of genital cone; deirids short, stout; vulvn $>650 \mu \mathrm{m}$ anterior to anus P. finlaysoni

3b. Dorsal lobe of bursa same length as laterals; spicule tips curved; 4 pairs of projections on posterior lip of genital cone; deirids setiform; vulva $<600 \mu \mathrm{m}$ anterior to anus

$P$. temperatus

4a. Dorsal lobe of bursa Jonger than laterals; spicule tips slightly curved; up to 10 projections on posterior lip; large lateral alae on anterior lip of genital cone; deirids short; female tail $>600 \mu \mathrm{m}$ in length ..... $P$. tropicus

4b. Dorsal ray same length as laterals; spicule tips very curved; 2 pairs of projections on posterior lip; small lateral alae on anterior lip of genital cone; deirids long; female tail $<300 \mu \mathrm{m}$ in length

$P$. aepyprymmis

\section{DISCUSSION}

Of the 4 valid species of Potorostrongylus, $P$. woyliei most closely resembles $P$. temperatus and $P$. finloysoni in which the buccal capsule is also placed within the lip region. Potorostrongylus wovliei is most similar to $P$. finloysonit in both species the dorsal lobe of the bursa is longer than the lateral lobes, the dorsial ray gives off laternl branches close to the bifurcation of the trunk, and there is a fringe of 6 bifid elements on the posterior lip of the genital cone. A notch in the wedge-shaped tip of the submedian lips distinguishes P. woyliei from P. finlaysoni and all other Potoro. strongylus species. Potorostrongylus woyliei is also differentiated from $P$. finlaysoni by shorter spicules (895, one-eleventh body length vs. 1,303 , one-tifth to one-seventh body length) and longer deirids (20 ys. 10). Female $P$. woyliei differ from $P$, finlaysoni in having the vulva closer to the anus (370-536 vs. 665790 ), an ovejector with the sphincter the longest element, and a shorter vagina (170-200 vs. $375-440)$. Potorostrongylus woyliei can be distinguished from $P$. temperatus in having 6 bifid rather than 8 setate elements on the posterior lip of the genital cone, shorter spicules $(895$, one-eleventh body length vs. 1,175 , one-eighth body length) and the dorsal lobe of the bursa longer than the lateral lobes. In female $P$. woyliei, the infundibulum is the shortest element of the ovejector, but in $P$. temperatts the infundibulum and vestibule are about the same length.

The fuurth-stage larva was found together with fifth-stage adult specimens in the stomach lumen of the host. The shape of the posterior end atlowed the identification of the worm as female. The cephalic extremity and the presence of esophago-intestinal diverticula indicated the fourth stage of development.

The presence or absence of esophago-intestinal diverticula has not been used in phylogenetic analyses of the Cloacinidae. Smales (2002) noted that such diverticula are present in the adalts of all genera comprising the tribe Labiostrongylinea except $P$ otorostrongylus. The presence of esophago-intestinal diverticula in a juvenile $P$. woylici (Fig. 5) suggests that this is the pleisonorphic state for the tribe and that their absence in adults is a derived state. This is consistent with the hypothesis that Potorostrongylles are derived from Labionultiplex Smales, 2002, a related genus common in the stomachs of macropodid marsupials (kangaroos and wallabies) (Smales, 2002).

Figures 1-16. Potorostrongylus wroyliei n. sp. from the brush-tailed bettong, Bettongia penicillata, in Westem Australia. 1. Anterior end, male lateral view deirid (D). 2. Cephalic end, dorsoventral view. 3. Cephalic end, lateral view. 4. En face view showing notched tips of submedian lips (arrow). 5. Juvenile female, hateral view showing esophago-intestinal diverticula (arrow). 6. Juvenile female, cephalic end, lateral view. 7. Deirid. 8. Genital cone, dorsal view. 9. Proximal end spicule. 10. Spicule tip. 11. Bursa, lateral view. 12. Spicule shearhs, dorsal view. 13. Bursa, end on. 14. Ovejector, lateral view showing vagina (V) vestibule (VE) 1 branch of sphincter $(S)$ and infundibulum (I). 15. Female posterior end, lateral view. 16. Dorsal ray showing branchlet. 
There are 7 extant species of potoroos and bettongs all of which have been surveyed for helminths (Spratt et al.. 1991) except the long footed potoroo, Potorous longipes Seebeck and Johnston, 1980, a rare species restricted to northeastern Victoria, Australia (Strahan, 1995). Of the 6 host species surveyed for helminths, no species of Potorostrongylus is reported from the burrowing bettong, Bettongia lesueur (Quoy and Gilimard. 1824), which is extinct on the mainland and found only on islands off the const of Westem Australia. The remaining 5 host species are each associated with 1 species of Potorostrongylus: $P$. tridatylus with $P$. finlaysomi, $B$, tropica with $P$. tropicus, $B$. penicillata with $P$. woyliei, $B$, gaimardi with $P$. temperatus, and $A$. rufescens with $P$. aepypryminus (Smales, 1997). In addition, incidental associations are reported for $A$. nufescens and $B$. gaimardi. Potorostrongylus finlaysoni was reported from the type host, $P$. tridactylus, and B. gaimardi on Maria Island, off the const of Tasmania, Australia (Smales, 1997). Infections in $B$. gaimardi are probably incidental associations resulting from host sympatry on the island. Potorostrongylus temperatus occurs in A. rufescens from New South Wales, Australia as well as $B$. gaimardi, the type host, from Tasmanin, Australia. The host distribution of $P$. temperatus may be relictual: $B$. gaimardi was distributed on mainland Australia as recently as the early twentieth century, occurring sympatrically with $A$, nifescens in New South Wales (Dennis and Johnson, 1995; Rose and Johnson, 1995). Additional survey is required to determine the host range and geographic distribution of $P$. temperatus, particularly on mainland Australia. Finally, an infecrion of $P$. tropicus is reported from an individual $A$. rufesciens in Queensland, Australia. Again, this is probibly an incidental infection resulting from sympatric overlap of $A$. rufescens with $B$. tropica, the normal hust of $P$. tropicus.

The potoroids and their labiostrongyiine parasites appear to have coevolved with 2 exceptions: the relationship between $P$. temperatus and its hosts, $A$. rufescens and $B$. gaimardi; and the relationship between $P$. tropicus and its hosts, $B$. tropica and $A$. rufescens. These associations may reflect incidental infections among sympatric host species, true host switching, or some combination of the 2 . Whatever the mechanisms involved, A. rufescens has developed the most complex relationship with its community of Potorostrongylus species: no mixed infections are known, but host--helminth association varies geographically.

\section{ACKNOWLEDGMENTS}

We thank R. Brazeile who collected the hosts and Dr. I. Beveridge who examined the material and undertook initial processing.

\section{LITERATURE CITED}

Beveridge, I. 1983. Taxonomic revision of the Zoniolaiminea (Popova) (Nematoda: Strongyloidea) from macropodid marsupials. Australian Jourtal of Zoology Supplementary Series 91:1-88.

Beveridge, I. 1987. The systematic status of Australian Strongyloidea (Nenlatoda). Bulletin de Muséum National d'Histoire Naturelle, Puris $4^{\circ}$ série 9:107-126.

Chilton, N. B., R. B. Gasser, and I. Beveridge 1997. Phylogenetic relationships of Australian strongyloid nematodes inferred from ribosomal DNA sequence data. Intemational Joumal for Parasitology 12:14811494.

Christensen, P. 1995. Brush-tailed bettong. Bcttongia penicullata Gray, 1837. Pages 292-293 in R. Strahan, ed. The Mammals of Australia. Reed Books, Chatswood, Australia.

Dennis, A. J., and P. M. Johnson. 1995. Rufous bettong, Aepypiymnis rufescens Gray, 1937. Pages 285-286 in R. Strahan, ed. The Mammals of Australia. Reed Books, Chatswood, Australia.

Rose, R., and K. A. Johnson. 1995. Tasmanian bellong, Bentongia gaimardi (Desmarest, 1822). Pages 287-288 in R. Strahan, ed. The Mammals of Alustralia. Reed Bnoks, Chatswood, Australia.

Smales, L. R. 1997. A revision of the genus Potorostrongy/hs Johnston and Mawson, 1939 (Nenatoda: Cloacinidae) from potoroos and betlongs (Marsupialja: Potoroidae) with the description of two new species. Systematic Parasitology 38:185-196.

Smales L. R. 2002. A cladistic analysis of the tribe Labiostrongylinea Beveridge, 1983 (Nematoda: Cloacinidae) purasitic in macropodoid marsupials (Marsupialia: Macropodoidea) with a redescription of Parazoniolaimus collaris Johnston and Mawson, 1939. Systematic Parasitology 51:179-197.

Spratt, D. M., I. Beveridge, and E. L. Walter. 1991. A catalogue of Australasian monotremes and marsupials and their recorded heiminth parasites. Records of the South Australian Museum Monograph Series 1. 105 pp.

Strahan, R. 1995. The Mammals of Australia. Reed Books, Chatswood, Australin. $756 \mathrm{pp}$. 